\title{
Public health and hygienic condition of retailers at fish markets in Sylhet Sadar of Bangladesh
}

\section{Md. Alamgir Hossain ${ }^{1}$, Md. Motaher Hossain ${ }^{1}$, Md. Golam Rasul ${ }^{2}$ and Mohammad Abu Jafor Bapary ${ }^{1}$,*}

${ }^{1}$ Department of Fisheries Technology and Quality Control. Faculty of Fisheries. Sylhet Agricultural University. Sylhet. Bangladesh. *Email: jafor_bau@yahoo.com.

${ }^{2}$ Department of Fisheries Technology. Bangabandhu Sheikh Mujibur Rahman Agricultural University. Gazipur. Bangladesh.

\begin{abstract}
The hygienic and sanitary conditions of majority of the retail fish markets are very poor and unhealthy that may have an impact on fish retailers. The present study was conducted in two retail fish markets located in Kajirbazar and Bondorbazar, in Sadar Sylhet, to assess the hygiene and sanitary condition of fish retailers. Information was collected through questionnaire interview and participatory rural appraisal (PRA) from the retailers and other value chain stakeholders. It was found that about $82 \%$ of fish retailers were permanent in these retail markets. The retailers are mainly involved in selling various species of fishes such as carps, catfishes, tilapia, koi, hilsa, shrimp and other small indigenous fishes. The sources of these fishes are mainly of nearby haors, river and ponds. The retailers get fishes from various suppliers and also collected from producers. The income level of fish retailers is relatively low although they are trying to improve their socio-economic conditions. Besides, about $9 \%$ of the retailers do not have any formal education whereas $70 \%$ and $21 \%$ have their education in primary and secondary level, respectively. Although the majority of the retailers were found literate, however, their knowledge on public health was seemed to be very poor. Due to lack of proper knowledge on public health, they are frequently affected by various diseases such as common cold, diarrhea, lesion, fever, skin disease and so on. Particularly, $48 \%$ of the fish retailers are affected by the lesion on hands, and $31 \%$ and $27 \%$ of retailers have been affected by the lesion between fingers or toes, respectively. About $20 \%$ of the retailers do not have adequate knowledge on fish quality or benefit of using ice in fish preservation in retail markets. Considering all together, the present study revealed that the retailers operated fish markets are ill-managed, unhygienic and unsatisfactory. The lack of proper fish preservation facilities, poor water supply and unplanned infrastructures are generally regarded as a noticeable problem in the retail markets. In addition, the lack of retailer's education, consciousness about fish quality, lack of training on hygienic and sanitary conditions are seemed to be involved in spoiling or deteriorating fish
\end{abstract}

Received April 6, 2019

Accepted

April 29, 2019

Released April 30, 2019

Full Text Article

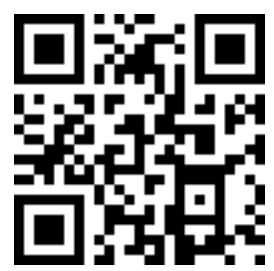

ORCID

(1) 0000-0002-5171-5191 Md. Alamgir Hossain

(ㄱ) 0000-0002-0318-8358 Md. Motaher Hossain

(1) 0000-0002-9057-6470 Md. Golam Rasul

(1) 0000-0001-8804-294X Mohammad Abu Jafor Bapary 
quality before reaching to the consumers. Therefore, the proper education and training on hygienic and sanitary conditions as well as sufficient knowledge on maintaining fish quality is required for retailers involved in fish retailing in the markets. It can be concluded that the improvement of relevant facilities of fish markets and proper supervision by respective authorities can ensure the better public health for retailers and safe fish food for consumers.

Keywords: Public health; Hygiene; Sanitation; Retailers; Socioeconomic conditions.

\section{Introduction}

Bangladesh has a long tradition as a fish producing country due to it's agro-ecologically nature. It is one of the world's leading fish producing country with an inland production of 3,251,796 metric tons and marine catch of 626,528 metric tons during 2015-2016 (FRSS, 2017). The total fish production for the year 2015-16 was above 3878324 metric tons (DoF, 2017). Although fish was harvested traditionally from the natural water bodies from ancient time, it has declined dramatically over the years due to various changes of environmental and anthropogenic factors. It has been found that the number of fish markets has been increased dramatically with the urbanization rapidly. Markets at all levels had retailing arrangements, that is, a group of retailers who sell fish to the consumers directly. The number of fish markets that run seven days in a week increased day by day due to the high demand of fisheries commodities. In general, the conditions of retail markets in urban and rural areas are not satisfactory due to presence of different unauthorized establishment near fish markets, lack of parking, space for keeping fish, unhygienic sanitary condition, poor drainage system and weak management chain.
Generally, fish marketing in the domestic market is not competitive in terms of the huge demand of fish in compare to supply to the market. The infrastructural facilities including fish landing, preservation or processing, wholesaling, or retailing often posing serious threats to public health because of inadequate and unhygienic operation system. However, the most severe marketing difficulties seem to occur in remote communities including lack of transporting system, icing facilities, poor road facilities. Moreover, in these markets the fish producers or traders are in particularly weak position due to presence of huge intermediaries. Public health is generally regarded as the science and art of preventing disease, prolonging life and promoting health through the organized efforts and informed choices of society, organizations, public and private, communities and individuals. It is concerned with threats to health based on population health analysis (Cuter and Miller, 2005).

Communicable diseases are still the major diseases in Bangladesh. Mortality and morbidity due to these diseases are very high. Infectious diseases like cholera, typhoid, tuberculosis, leprosy, tetanus, measles, rabies, venereal diseases and parasitic 
diseases like malaria, filariasis, and worm infestations are responsible for major morbidity (Nickson et al., 1998). Compared to the general public health situation in terms of sanitation, drinking water supply has been improved a lot in Bangladesh. However, the existing situation of public health of fish market stakeholders, particularly of retailers has not been developed yet although those issues are closely related to the fish quality as well as retailer and consumers safety.

Considering these points in this study was we sought to address the current status of fish market and socioeconomic condition of fish retailers and assessed the various issues of public health being faced by the fish retailers. In addition, we outlined the relevant measures being taken to develop public health situation of fish retailers.

\section{Methodology}

\section{Selection of the study area and target group}

The study was conducted based on market survey for obtaining information through a sample survey of the fish retailers. The survey was done in the two important markets of Sylhet Sadar in Sylhet district which is located in the north-eastern region (Figure 1). A large number of people (retailer) are engaged in fish marketing in this region due to the presence of huge fisheries resources including haors, rivers, ponds as well as the availability of diversified fish species.

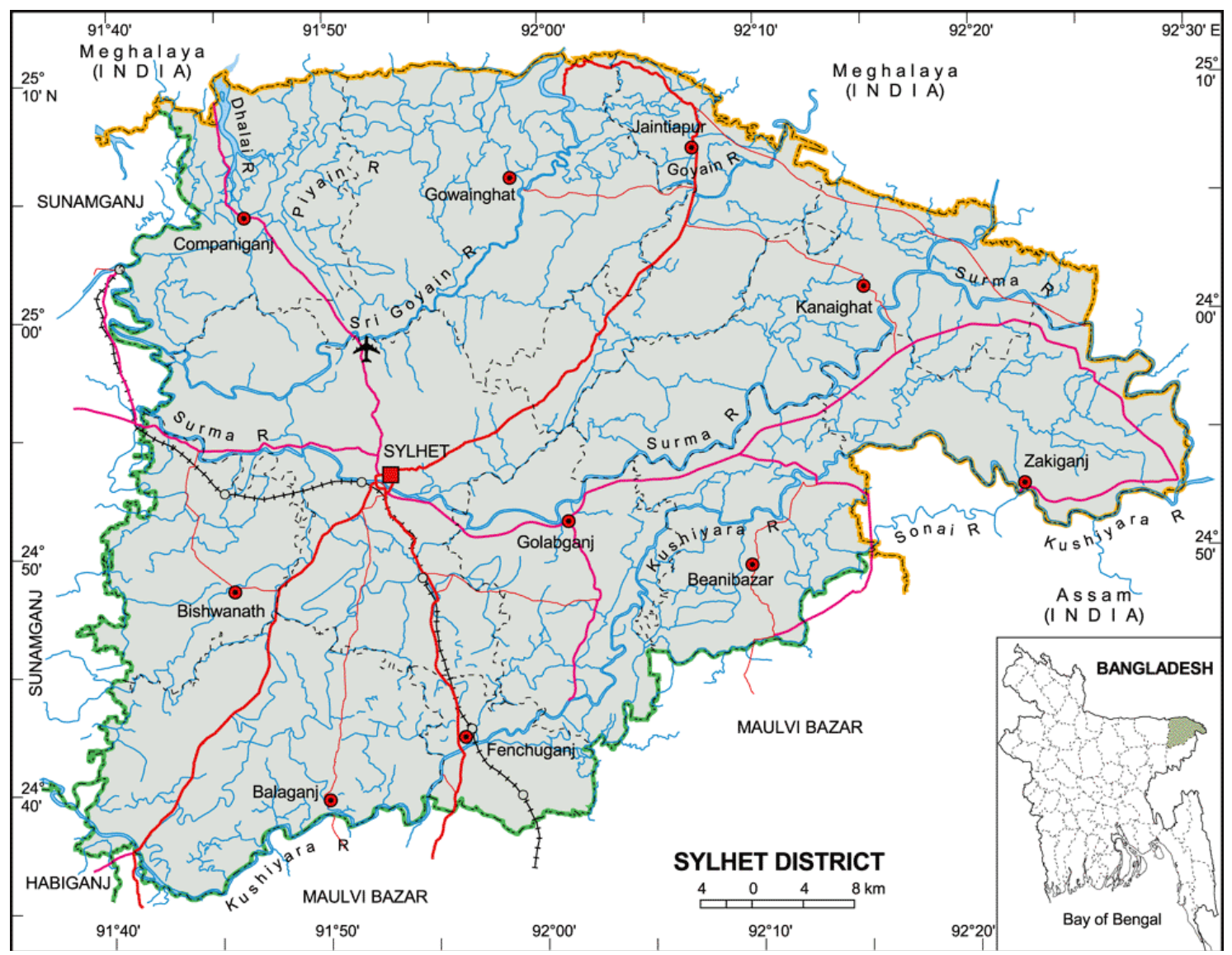

Figure 1. Map showing the area used for study purpose. 


\section{Data collection and questionnaire design}

A total of 30 fish retailers were interviewed in two different markets. To collect pertinent data, the single interview technique such as primary data was collected directly from the fish retailers using structured questionnaire and field visits.

A well-structured questionnaire was prepared for interviewing with fish retailers. In survey, a questionnaire is a cardinal tool for collection of necessary appropriate information. In this study, questionnaires were prepared in consistent with the objectives for collecting germane information.

\section{Data collection methods}

Collection of accurate and reliable data and other necessary information from the field is considered as a tough task but the success of survey depends on reliability of data. Therefore, utmost care was given to complete it properly. In order to collect relevant information, interview technique was followed. For the study, a combination of questionnaire interviews, participatory rural appraisal (PRA) tools such as focus group discussion (FGD) with key informants were used for appropriate data collection.

\section{the data}

\section{Processing and tabulation of}

The collected data were summarized and processed for analysis. These data were verified to eliminate all possible errors and inconsistencies. Tabular technique was applied for the analysis of data by using simple statistical tools like averages and percentages. Finally, the processed data were transferred to a master sheet from which classified tables were prepared revealing the finding of the study.

\section{Analysis of data}

Mainly the tabular analysis technique was used in this study. The data were presented mostly in tabular form, because of the simple analytical techniques, widely used and easy to understand. For processing and analysis purpose, MS Excel and MS word had been used. Tables and pie-charts have been used for presenting information in the text of the thesis.

\section{Results}

\section{Source of fish in the market}

About 264 freshwaters and 475 marine water species are available in the water bodies of this country. During the present study in 2 retail markets, all the fish species were not found while the available species were as rui (Labeo rohita), catla (Catla catla), mrigal (Cirrhinus cirrhosis), silver carp (Hypophthalmichthys molitrix), common carp (Cyprinus carpio), hilsa (Tenualosa ilisa), bata (Labeo bata), koi (Anabas testudineus), sing (Heteropneustes fossilis), African magur (Clarias gariepinus), shorputi (Puntiuss sarana), bele (Glossogobius giuris), tilapia (Oreochromis mossambicus), golda (Macrobracium rosenbergii), tengra (Mystus vittatus), shol (Channa striata), taki (Channa punctata), pangus (Pangasius hypophthalamus), bhetki (Lates calcarifer), poa (Otolithoides pama), etc. The fishes were mainly sourced from river, pond, haor, beel and canal and nearby waterbodies (Figure 2). In most of the time, retailers did not maintain hygienic condition and proper ratio of ice with the fish they sold. 


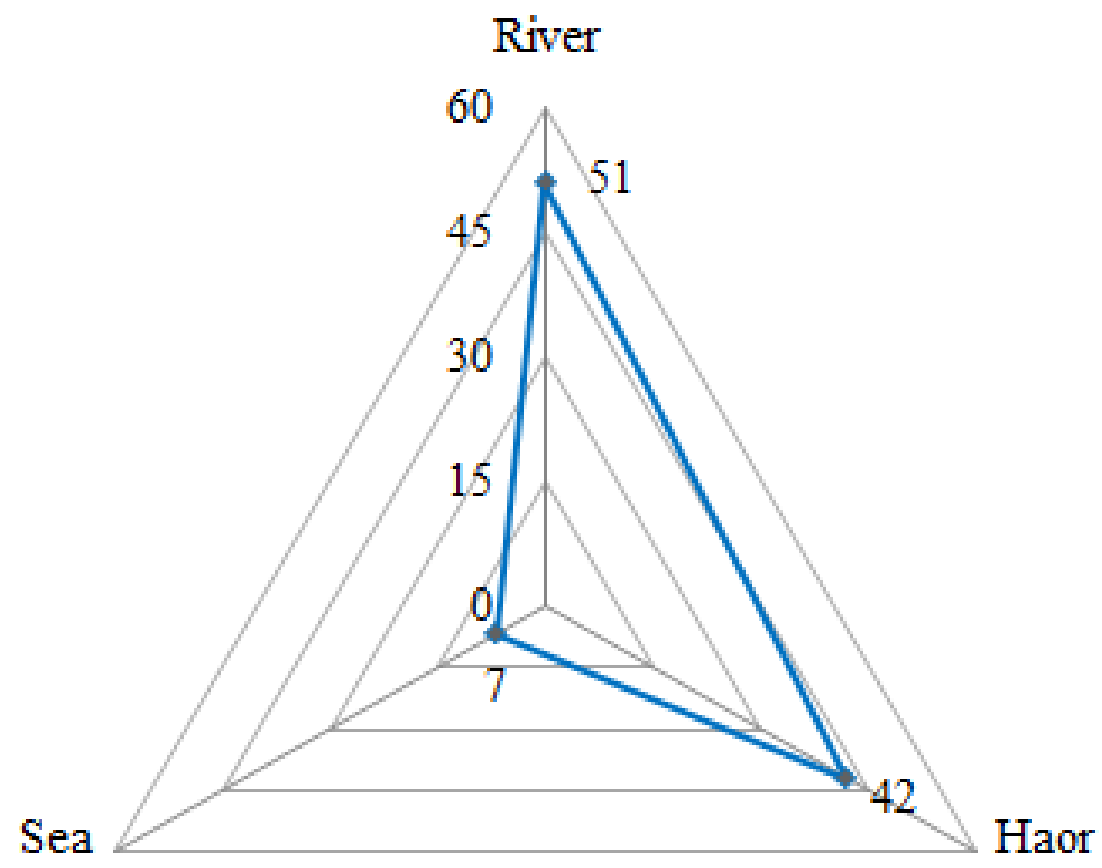

Figure 2. Percent of source of fish in retail market.

\section{Transportation system}

The quality of fish transported is a decisive criterion. The fish usually transported by using truck from far distant areas whereas they used van, easy bike, rickshaw and boat to carry out the fish from nearer areas. In maximum cases, they did not maintain the hygienic condition and the appropriate ratio of ice to fish.

\section{Use of ice}

The fish retailers mainly use block ice after crushing. Some ice factories developed besides the fish markets. It was found that out of 30 respondents, about $95 \%$ of fish retailers used block ice. They don't maintain appropriate ice-fish ratio.

\section{Socio-economic status of the fish retailers \\ Education level. Education is an} important factor in changing attitudes and in motivation. The education level of fish retailers was found very low. They have lack of knowledge about the quality of fish and fisheries products, sanitation and public health. They did not follow any prescribed rules and regulation for selling fish. They did not maintain the proper ratio of ice while icing the fish. The observation of the present study revealed that only $9 \%$ of fish retailers were completely illiterate whereas $70 \%$ and $21 \%$ went to primary and secondary school, respectively (Figure 3). 


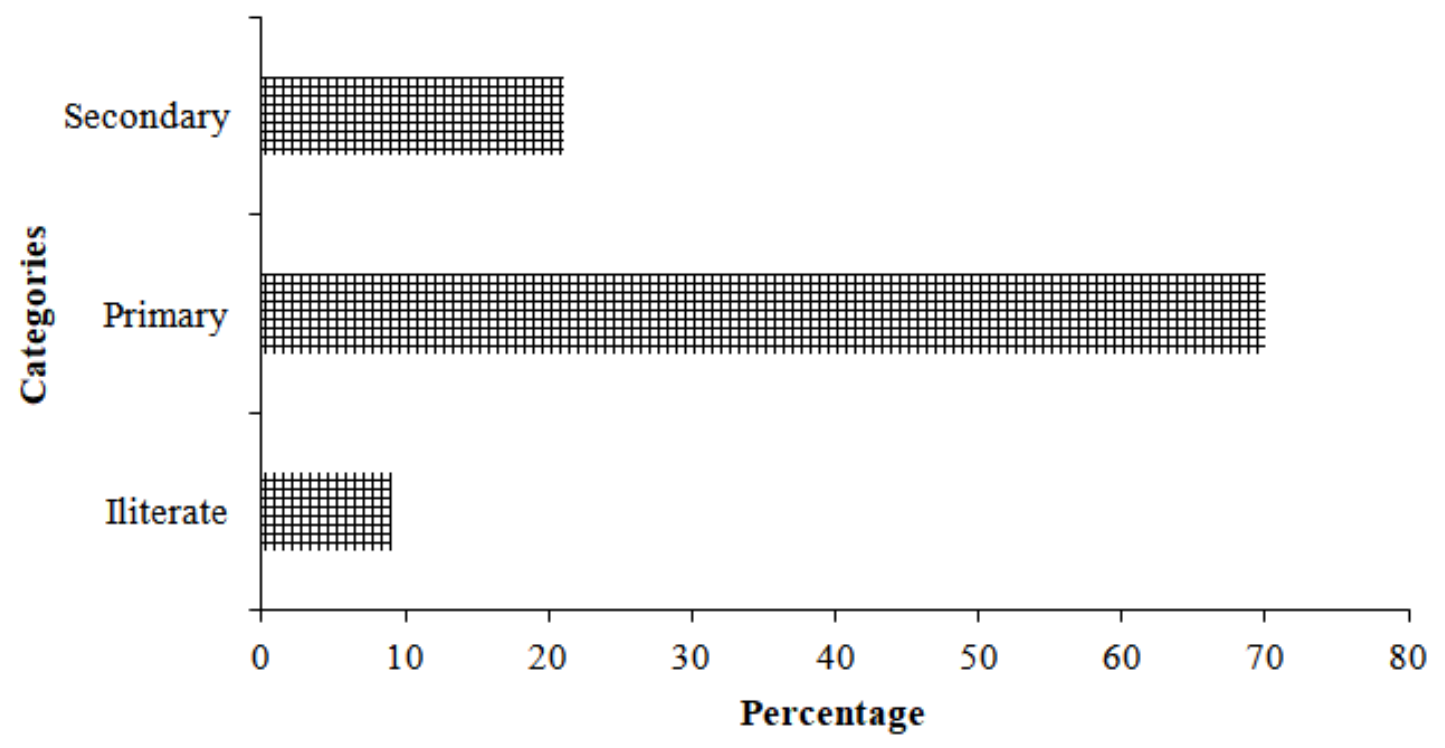

Figure 3. Percent of respondents the education level of the fish retailers.

\section{Occupation diversity among}

fish retailers. The majority of the fish retailers are solely engaged in selling of fish to the customers. They sold fish two times daily as morning and the evening. Firstly, they bought fish from the farmers or fishermen by auctioning or other local system and then sold it directly to the customers. Some fish retailer had secondary occupation beside fish selling such as vegetable farming, animal husbandry, daily worker etc. Especially, small scale fish retailers had other occupation while large scale fish retailers usually did not engage any other occupation.

Income level. Income level of fish retailers was also evaluated to understand their socio-economic status. Income is generally regarded as the consumption and savings opportunity gained by an entity within a specified timeframe, which is usually expressed in monetary terms. The income level of fish retailers was not sufficient for their family. Most of the fish retailers live below poverty line and their economic condition was found not good.

\section{Public hea
retail fish market}

It was demonstrated in the present study that health problem was one of the major occurrence to the fish retailers working in the retail fish market. Fish retailers are commonly infected by several diseases such as common cold, lesion between fingers, lesion between toes, and some other viral and bacterial disease. The retailers usually faced these kinds of problems due to continuous using of water for washing and refreshing the fish. It is suspected that they are infected by many serious bacteria, fungus, protozoan or viruses which are mainly carried by fish. Thus, it is suspected that the consumer as well as their family members can be infected by these diseases from the fish retailer, if this situation cannot be solved immediately.

Common cold disease. The common cold (also known as nasopharyngitis, rhinopharyngitis, acute coryza, head cold, or simply a cold) is a viral infectious disease of the upper 
respiratory tract which primarily affects the nose.

Cough. A cough is a sudden and often repetitively occurring reflex which helps to clear the large breathing passages from secretions, irritants, foreign particles and microbes. Various virus and bacteria are responsible for cough which is transmission from fish and water. Melting ice into water is very cold and sometime it creates cough to the retailers. Out of 30 respondents, about $45 \%$ fish retailers were affected by cough.

Coryza. Coryza is irritation and inflammation of the mucous membrane inside the nose. Coryza is commonly caused by a viral or bacterial infection, including the common cold, which is caused by Rhinoviruses, Coronaviruses etc., or bacterial sinusitis, which is commonly caused by Streptococcus pneumonia and some other bacteria. Due to unconsciousness, sometimes it creates serious problem such as pneumonia. Out of 30 respondents, about $22 \%$ of the fish retailers are affected by coryza.
Diarrhoea. The occurrence of diarrhoea was also frequent among the fish retailers. The loss of fluids through diarrhoea can cause dehydration and electrolyte disturbances such as potassium deficiency or other salt imbalances. There are many causes of infectious diarrhoea, which include viruses, bacteria and parasites. Their hands are very dirty and they always bear various bacteria, virus, fungi and other protozoan animals which come from fish. Campylobacter sp. are a common cause of bacterial diarrhoea, but infections by Salmonella sp., Shigella sp. and some strains of Escherichia coli are also a frequent cause. The majority fish retailers did not wash their hands clearly. Sometime they wash their hand only water but did not use soap. As a result, they are affected by bacteria and can cause disease like diarrhea. Out of 30 respondents, about $32 \%$ of fish retailers are affected by diarrhoea.

Lesion. A lesion is any abnormality in the tissue of an organism (in layman's terms, "damage"), usually caused by disease.
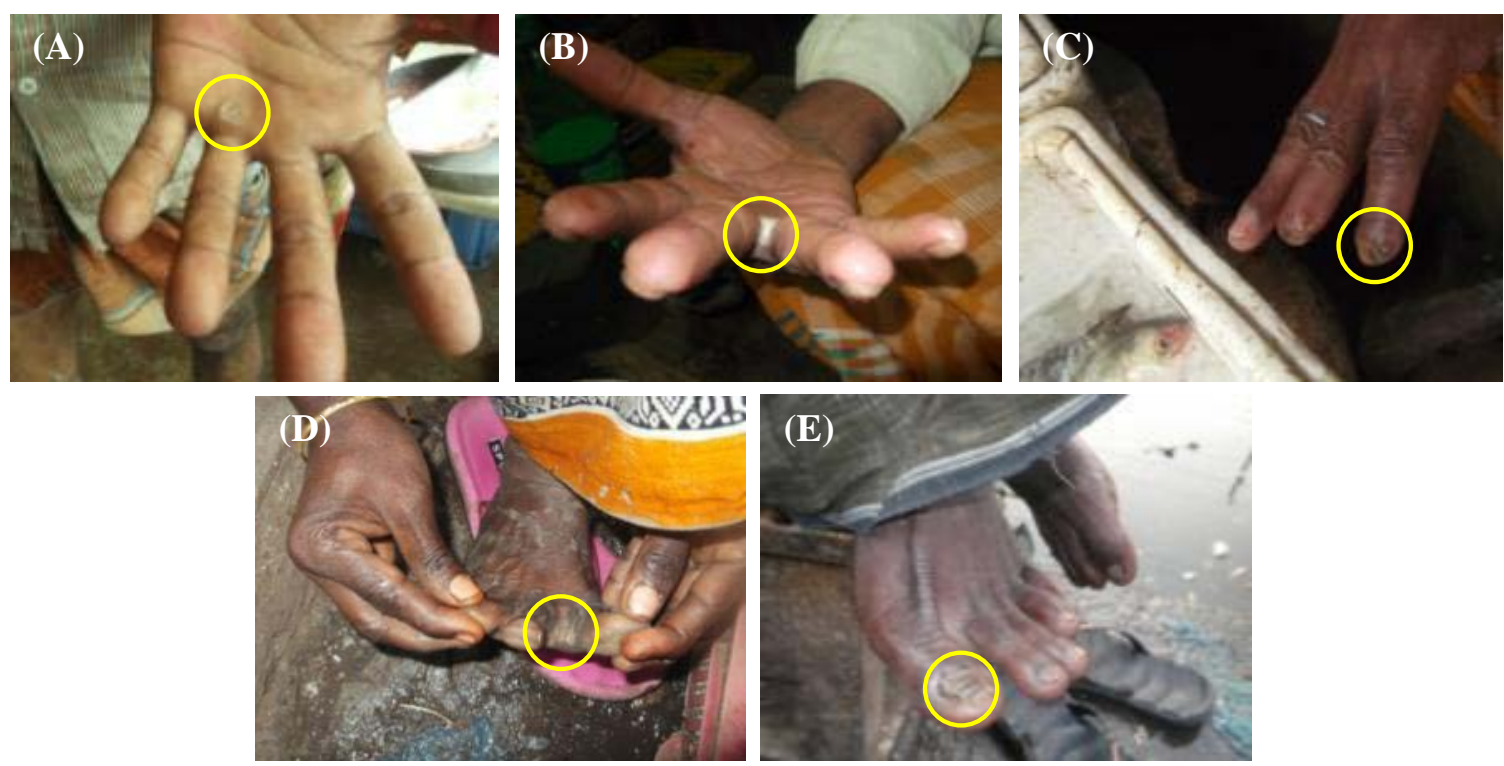

Figure 4. (A) Lesion on hands, (B) lesion between fingers, (C) lesions on the tip fingers, (D) lesion between toes and (E) lesion on the nail and tip of toes. 
Lesion on hands. Most of the fish retailers were affected by this disease. During rainy season, it increases epidemically to the fish retailer due to higher humidity and wet condition causing lesion in hands and the secondary infection through fungus. Some place in hands turn into whitish color and cause further lesion. Various bacteria grow in that lesion which comes from fish. Out of 30 respondents, about $48 \%$ of the fish retailers were affected by the disease of lesion on hands (Figure 4).

\section{Lesion between fingers.}

Majority fish retailers are facing this serious disease because they always get water and it persists between the fingers for long time. Sometimes they use mustard oil to prevent this disease. The disease was spread due to the secondary infection caused by the fungus. Out of 30 respondents, about $31 \%$ of fish retailers were faced the disease of lesion between their fingers (Figure 4).

Lesion on the tip fingers. Some fish retailers have got this disease but this was not the major health problem. Some pathogenic bacteria can grow in that place and it can cause disease in the intestinal organ while retailers take food. Out of 30 respondents, about $5 \%$ of fish retailers were attacked by the disease of lesion on the surface of the fingers (Figure 4).

Lesion between toes. The fish washed water and the melting ice water is drained out above the platform. As a result, the fish retailers faced the disease of lesion between toes. Out of 30 respondents, about $27 \%$ of the fish retailers faced the disease of lesion between their toes (Figure 4).

Lesion on the nail and tip of toes. It is very common for fish retailers because the water bearing bacteria create the disease. Sometimes fungus attacked the injured areas and can create serious problems. Out of 30 respondents, about $13 \%$ of fish retailers faced the disease of the lesion on the nail and tip of toes (Figure 4).

\section{Hand washing (hygiene maintenance)}

Hand washing can prevent various diseases such as diarrheal disease (which can include shigellosis, typhoid and cholera), acute respiratory infections etc.

Hand washing after urination. After urination majority fish retailer did not wash their hand. Most of the male fish retailers did not wash their hands but female fish retailers washed their hands in that case. More than $72 \%$ of fish retailers did not wash their hand after urination, out of 30 respondents.

Hand washing after toilet use. Washing hand with soap is very much important after toilet use because hand washing with soap is the most effective and inexpensive ways to prevent diarrhea. Washing hands with water alone is significantly less effective than washing hands with soap in terms of removing germs. In this case, cent percent of fish retailers used to use soap after toilet use.

Washing of utensils and
platform
In fish market, utensils and
platform washing is very much
important for preventing contamination
as well as bacterial growth.

Source of washing water. The washing water using by the fish retailers is usually taken from nearest river and deep tubewells. Kajirbajzar fish market is situated near the river. For this reason, the fish retailer frequently uses river water for washing purposes. Lalbazar fish market are placed in main town and the fish retailers use tubewell water for washing fish and their platform. Out of 30 respondents, about $62 \%$ and $38 \%$ of 
fish retailers used river water and tubewell water for washing, respectively.

Washing frequency. Some fish retailers washed their utensils and platform daily but some others did it twice daily. It was observed that the permanent fish retailers washed two times whereas temporary retailers washed single time. Out of 30 respondents, about $82 \%$ of the fish retailers washed once daily and $18 \%$ of the fish retailers washed twice daily of their fishing utensils and platform.

Support of City Corporation to retailers. The condition of fish market is very poor and dirty. Conditions in these markets are not satisfactory in respect of sales areas, parking, sanitation, watersupply, drainage, cleaning, washing, maintenance and repairs. As a result, the fish retailers are easily infected by disease with various bacteria, fungus and other pathogens. However, City Corporation gives little support to these fish markets. This should not really happen; therefore, City Corporation should take immediate steps to improve the environment and condition of retail fish markets.

\section{Discussion}

fish

\section{Background of retail market of}

Bangladesh is a riverine country where about 230 small and big rivers are spread throughout the country like a net (Rounak and Rahman, 2013). Moreover, the vast inland water bodies made this country resourceful with a variety of fish species. The north-east region of Bangladesh is traditionally enriched with a number of fishes. The main source of fish in the retail markets of north-east region of Bangladesh, are rivers and haors although a considerable amount of fish comes from ponds and sea. It has been observed that different types of fishes are available in the retail market such as rui (Labeo rohita), catla (Catla catla), mrigal (Cirrhinus cirrhosis), silver carp (Hypophthalmichthys molitrix), common carp (Cyprinus carpio), ilish (Tenualosa ilisha), bata (Labeo bata), koi (Anabas testudineus), shing (Heteropneustes fossilis), African magur (Clarias gariepinus), shorputi (Puntiuss sarana), bele (Glossogobius giuris), tilapia (Oreochromis mossambicus), golda (Macrobracium rosenbergii), tengra (Mystus vittatus), shol (Channa striata), taki (Channa punctata), boal (Wallago attu), pangus (Pangasius hypophthalamus), bhetki (Lates calcarifer), poa (Otolithoides pama) etc.

Fish is highly perishable food item; needs utmost care and attention for maintain its quality. The habitats of fish are completely different from its postharvest environments and its quality depends on several extrinsic and intrinsic factors, such as composition, degree of spoilage, damage, deterioration during harvesting, cleaning, washing, handling, preservation, processing, storage, transportation, distribution and marketing (Hussain, 1971). Due to large supply of fish and its perishable nature makes the fish market very unhygienic.

Some factors should be taken into consideration for keeping the fish quality before selling in the retail markets. It is generally recommended that fish transportation system should be improved to keep the quality at acceptable level. Moreover, use of appropriate type and ratio of ice should be ensured for fish transportation and preservation. Lowering temperature with ice is a popular method for fresh fish preservation. Flake ice has the highest cooling rate whereas block ice has the slowest performance. The uniform particle size and large surface squares of flake ice provides the better heat transfer for cooling fish (Huss, 1994). However, when the fishes are transported from farm to the auction market, no or little ice is used which ultimately deteriorates the quality of fish and also make the retail market conditions unhygienic. 


\section{Socio-economic status of the fish retailers}

Education is an important factor to change the attitudes. Literacy status plays a vital role in an efficient participation and operational skill in agricultural activities of the retailers. Education of fish retailers is necessary to have better access to the relevant technical information and to make rational economic discussion. Fish retailers were categorized into three major classes on the basis of level of education (Zaman et al., 2006). In the present study, out of 30 fish retailers, about $9 \%$ of them had no education, $70 \%$ had education at primary level and 21\% had secondary level of education. As majority of the retailers were educated although at the primary level, this has potential to make them further educated in the maintenance of hygienic condition in the fish market. Similar results reported by Adhikary et al. (2018).

Age of the decision-maker is an important factor for changing the existing situation of retail markets. Therefore, the age of the fish retailers was also studied. Only four percent retailers were in 15 to 24 years old whereas eighty-nine percent of the fish retailers were in 25 to 50 years old. Seven percent of farmers were $50+$ to 60 years of age. As the majority of the retailers were of middle age group, therefore training, extension and spread of knowledge would be quite effective (Bhaumic and Saha, 1994) to build awareness in hygiene of fish retail market. Our findings is similar with Trina et al. (2016).

As Bangladesh is an agro-based country, the majority of the people of the studied area adopt agriculture as their main profession. Most of the fish retailers in this study area were found to involve in fish selling or agriculture as main source of income and livelihood. Women were also involved to sell fish and in other relevant activities such as cleaning, processing, washing or weighing of fish (Scones, 1998). It was, however, observed that the retailers in north east region in Bangladesh are also engaged in several secondary activities such as agriculture, fishing, sewing, service and other business beside their primary occupation of fish retailing.

\section{Public health and hygiene in retail fish market}

The health condition is the reflection of the livelihood status of the fish retailers. Although most of the fish retailers were literate but they have very infinitesimal knowledge about public health and hygienic condition. Due to lack of knowledge about public health, they were found affected by various diseases such as common cold (cough, coryza), diarrhoea, lesion (lesion on hands, lesion between fingers, lesion on the tip fingers, lesion between toes, lesion on the nail and tip of toes etc.) and skin disease. Most of the fish retailers were found severely affected by lesion on hands, lesion between fingers and toes. During rainy season, the affected rate usually increases because of higher humidity and wet condition of weather and the water persists between the fingers and toes for long time. They are likely to carry bacteria in their gut, nose, mouth, ears, and hair and on their skin. It is general perception that these bacteria are quite normal and do not affect the fish retailers and the coworkers., It is reasonable to assume that these microbes are transferred to the fish food cause deterioration of fish quality and spoils them before reaching to consumer level. It was also noticed that they have lack of knowledge about sanitation system and sometimes they do not use water after urination and using toilet. Our findings are more or less similar with Sharif et al. (2015).

\section{Conclusion}

The results of the present study revealed that almost all fish markets operated by the fish retailers are illmanaged, unhygienic and unscientific. 
There is no proper handling, washing, cleaning, icing or re-icing facilities for fish. Very little attention is paid by fish transporters for post-harvest management or improvement of the resources, rather more interested in earning more revenue at the cost of the fishermen and the consumers. Therefore, almost all of the fish markets are not facilitated with modern infrastructural facilities and sometimes it does not have any overhead covering. These poor infrastructural facilities of fish harvesting, landing, handling, preservation, transportation, distribution and marketing are mostly responsible for fish poor hygiene and sanitation condition of fish retailers as well as maintain fish quality in retail markets. Similar fish marketing problems were investigated by Aktar et al. (2010).

\section{Conflict of interest}

The authors declare that there are no conflicts of interest.

\section{Reference}

Adhikary, M. R.; Rahman, M. A.; Asif, A. A.; Adhikary, R. K. Socio-economic status of fish retailers in Jashore sadar, Bangladesh. AsianAustralasian Journal of Food Safety and Security, v. 2, p. 100-108, 2018.

Aktar, N.; Bashar, M. A.; Islam , M. T.; Barman, A. C.; Tehjib, M. S. Fish marketing system and socio-economic status of fish retailers in three markets of Puthia Upazila, Rajshahi District, Bangladesh. Journal of Agroforestry and Environment, v.3, p. 223226, 2010.

Bhaumik, U.; Saha, S. K. Perspective on socioeconomic status of the fishermen engaged in fishing in the estuaries of Sundarbans. Environmental Ecology, v. 12, p. 181-185, 1994.

Cuter, D.; Miller, G. The role of public health improvements in health advances: The twentieth century United States. Demography, v. 42 , p. 1-22, 2005. https://doi.org/10.1353/dem.2005.0002

DoF - Department of Fisheries. Fisheries and Livestock Ministry, Dhaka, Bangladesh. Sankalan, Matsha Saptaho: DoF, 2017.

FRSS - Fisheries Resources Survey System. Yearbook of Fisheries Statistics of Bangladesh. Bangladesh: FRSS, Department of Fisheries, 2017. v. 33.

Huss, H. H. Assurance of seafood quality. Rome: FAO, 1994. (FAO fisheries technical paper, 334).

Hussain, M. M. The commercial fishes of the Bay of Bengal. UNDP Project PAK22, Pub. No. 1, 1971.

Nickson, R.; McArthur, J.; Burgess, W.; Ahmed, K.M.; Ravenscroft, P.; Rahman, M. Arsenic poisoning of Bangladesh groundwater. Nature, v. 395, p. 338, 1998. https://doi.org/10.1038/26387

Rounak, A.; Rahman, M. A. Transboundary river water for Ganges and Teesta rivers in Bangladesh: An assessment. Global Science and Technology, v. 1, p. 100-111, 2013.

Scones, I. Sustainable rural livelihoods: A frame work for analysis. Brighton, UK: IDS, 1998. (IDS working paper, 72).

Sharif, B. M. N.; Asif, A. A.; Vaumik, S.; Zafar, M. A.; Islam, M. M.; Samad, M. A. Socioeconomic condition of fish farmer and trader at the village of Pitamborpur in Chaugachha Upazilla in Jessore, Bangladesh. International Journal of Fisheries and Aquatic Studies, v. 3, p. 212-217, 2015.

Trina, B. D.; Rasul, M. G.; Hasan, M. M.; Ferdous, J.; Ferdausi, H. J.; Roy, N. C. Status of fish biodiversity and livelihood of fisher's community in Dekhar Haor of Bangladesh. American-Eurasian Journal of Agricultural and Environmental Sciences. v. 16, p. 14171423, 2016.

Zaman, T.; Jeweland, M.A.S.; Bhuiyan, A. S. Present status of pond fishery resources and livelihood of the fish farmers of Mohanpur Upazilain Rajshahi District. University Journal of Zoology, Rajshahi University, v. 25 , p. $31-35,2006$. 